[Technical Paper]

\title{
Evaluation of Residual Stress and Warpage of Device Embedded Substrates with Piezo-Resistive Sensor Silicon Chips
}

\author{
Younggun Han*, Osamu Horiuchi*, Shigehiro Hayashi**, Kanta Nogita**, Yoshihisa Katoh*, \\ Kyosuke Nanami***, and Hajime Tomokage, ${ }^{* * *, * * *}$ \\ *Center of System Integration Platform Organization Standards, Fukuoka University, 1963-4 Higashi, Itoshima 819-1122, Japan \\ **Research Center for Three Dimensional Semiconductors, 1963-4 Higashi, Itoshima 819-1122, Japan \\ ***Department of Electronics Engineering \& Computer Science, Fukuoka University, 8-19-1 Nanakuma, Jonan-ku, Fukuoka 814-0180, Japan
}

(Received July 31, 2015; accepted November 4, 2015)

\begin{abstract}
The residual stress and warpage of a device embedded substrate (DES) is evaluated using a Si chip including a piezoresistive sensor. Two types of DESs are fabricated to investigate the effect of substrate structure on residual stress: a device mounted on the surface of a core substrate (core surface mounted type DES) and a device placed inside a through cavity of a core substrate (core cavity type DES). Both DESs have four conductor layers with two build-up ABF (Ajinomoto Build-up Film) layers. For the core cavity type DES, the effect of cavity clearance from $0.15 \mathrm{~mm}$ to $1 \mathrm{~mm}$ between the core wall and embedded chip is also investigated. The embedded devices are $9 \times 9 \mathrm{~mm}^{2}$ piezo-resistive sensor chips of $200 \mu \mathrm{m}$ in thickness, and the core is adjusted to the Si chip thickness. The residual stress induced from the fabrication process is obtained from measuring the resistance value of the piezo-resistive sensor before and after chip embedding. After measuring the residual stress, the warpage for each type of DES is observed using the shadow moire interferometry method with the temperature changing from $25^{\circ} \mathrm{C}$ to $260^{\circ} \mathrm{C}$. The relationship between the residual stress and warpage is discussed with respect to the substrate structure symmetry and balance.
\end{abstract}

Keywords: Device Embedded Substrate, Core Cavity Type, Residual Stress Evaluation, Piezo-resistive Sensor, Warpage

\section{Introduction}

Device embedded substrates have been attracting considerable industrial interest in the field of portable and wireless electronics because of the small form factor, low power consumption, good electrical performance, and short time-to-market.[1] At present, passive device embedded substrates are under mass production and active device embedded substrates are gradually becoming popular. Since the first active device-embedded substrate, the bumpless build-up layer (BBUL),[2, 3] was reported by Intel, various other types have been reported, including the integrated module board (IMB) by Helsinki University,[4] chip-in-polymer (CiP) by Fraunhofer IZM, [5, 6] the chip-in-substrate package (CiSP) by ITRI,[7] embedded active and passive chip-last (EMAP-CL) by the Georgia Institute of Technology,[8] and others. All these deviceembedded substrates reported good signal performance and high reliability; however, challenges remain in their development, including low production yield from process difficulties as well as scaling to finer pitches. These reports placed devices either inside or on the substrate. In packages that bury devices inside the core substrate, like the BBUL, misalignment is the biggest obstacle to scaling down the pad pitch of the embedded active device. This alignment problem can be alleviated by increasing the pad size, but doing so prevents scaling down to a finer pitch. In packages that mount devices on the core substrate, aligning the via to the bond pad is easier, but some problems remain, such as the thinning of Si chips, leveling of epoxy resin without breaking chips, and substrate warpage.[7, 9]

In our previous paper,[10] we demonstrated the fabrication feasibility and reliability of the new core cavity type of device embedded substrate, where the device is embedded inside the through cavity in the core (EiCC). Compared with the core surface mounted type DES, EiCC can more easily produce a thinner device-embedded substrate, 


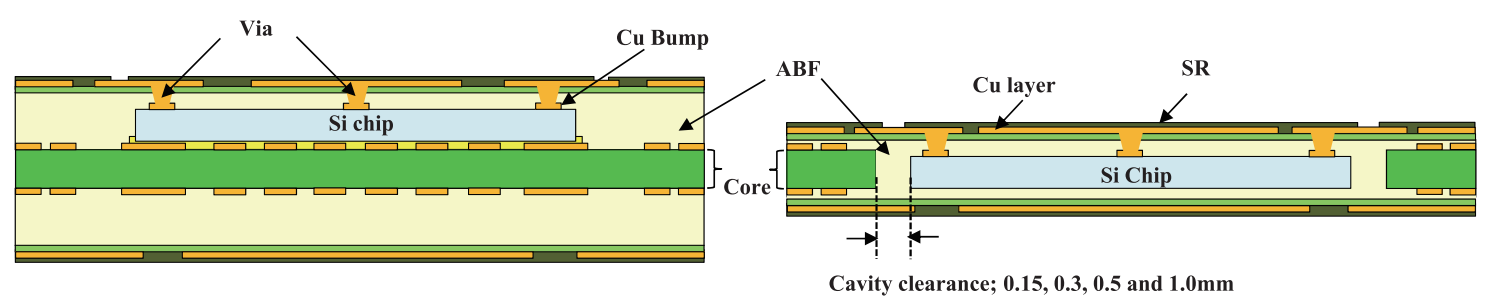

A. Core surface mounted type DES

B. Core cavity type DES

Fig. 1 Schematic cross sections of two types of device embedded substrate with piezo-resistive sensor embedded Si chip.

giving EiCC-based devices better form factor and electrical performance than core surface mounted embedded substrates. Moreover, from the concept of EiCC, it is possible to obtain a balanced epoxy resin structure inside a substrate and consequently warpage problem can be solved.

The process induced residual stress is closely related to the warpage and reliability of IC packages and substrates. By evaluating the residual stress, it is possible to optimize the material and structure design of a package for good reliability and low warpage. The residual stress evaluation of IC packages has generally been conducted using finite element method (FEM) simulation,[11-13] nevertheless the FEM simulation is not correct enough to evaluate a large complicated structure exactly and is time-consuming. Consequently, several studies on real measurement of residual stress using a piezo-resistive sensor embedded $\mathrm{Si}$ chip have been reported.[14-16] The piezo-resistive behavior of Si has been studied extensively [17-20] and in a package system, the residual stress evaluation can be determined by measuring the change in resistance before and after the packaging process.

In this paper, the warpage issue of EiCC related to the residual stress will be discussed in detail. Using the piezoresistive sensor embedded $\mathrm{Si}$ chips (STAC TEG-0101JY: WALTS Co., Ltd), we characterized the core cavity type DES in terms of the process residual stress, comparing this to the core surface mounted type DES. For the core cavity type DES, the effect of the cavity clearance between core wall and embedded chip on the residual stress was also investigated. The schematic cross sections of the two types of DESs for residual stress and warpage evaluation are shown in Fig. 1. From the stress measurements and cross-section observations, the relationship between the residual stress and the structure of DES will be investigated. In addition, the effect of material properties on the residual stress results will be discussed. Finally, after observing the warpage of each type of DES using the shadow moiré interferometry method, the mechanism of the warpage performance under the as-received state and the elevated temperature circumstance will be discussed in depth with the residual stress evaluation results.

\section{Experimental Details}

The fabrication process flows of two types of DES, that is, the core surface mounting type and the core cavity type, are shown in Fig. 2. For both types of DES, fabrication begins with a 200- $\mu$ m-thick FR4 core (MCL-M-679FG, Hitachi Chemicals, Japan) of $510 \times 407 \mathrm{~mm}^{2}$. First, through holes (THs) for alignment were mechanically drilled. After drilling, the core substrates were desmeared using $\mathrm{KMnO}_{4}$ alkali chemical etching, and the patterning of the core layer followed (layers 2 and 3). Using a router, through cavities (core cavity type only) were then drilled to make clearances of $150 \mu \mathrm{m}, 300 \mu \mathrm{m}, 500 \mu \mathrm{m}$ and $1 \mathrm{~mm}$ on all four sides to prevent direct contact between the embedded device and core substrate. After the cavity machining, the core substrate was divided into four panels, each $250 \times 190$ $\mathrm{mm}$, for post-processing. Every process panel had 24 pieces of DESs and each of them is $27 \times 27 \mathrm{~mm}^{2}$ size. Afterwards, the debris from machining were chemically removed and the $\mathrm{Cu}$ surface was roughened by chemical treatment.

After completing the core layer, the piezo-resistive sensor Si chip was mounted face-up on the core surface using non-conductive paste (EN-4900GC Hitachi Chemical) for the surface mounting type. For the core cavity type, after a temporary adhesive tape, which was a $25 \mu \mathrm{m}$ thick polyimide film with a $6 \mu \mathrm{m}$ adhesive layer (TRM 6250L, Nitto Denko, Japan), was laminated onto the top surface (layer 2) of the core, the Si chip was mounted face-down on it. The schematic image of the piezo-resistive sensor chip is shown in Fig. 3 together with the bump/pad structure of the chip. The Si chip was $9 \times 9 \mathrm{~mm}^{2}$ size and consisted of nine unit chips of $3 \times 3 \mathrm{~mm}^{2}$ size, where each chip had two piezo-resistive sensors formed in the $x$ - and $y$-directions located in the chip center (red color) and a corner (blue 
(1) Core preparation \& mechanical drilling

- size : $407 \mathrm{~mm} \times 510 \mathrm{~mm} \times 0.2 \mathrm{~mm} t$

- TH for alignment

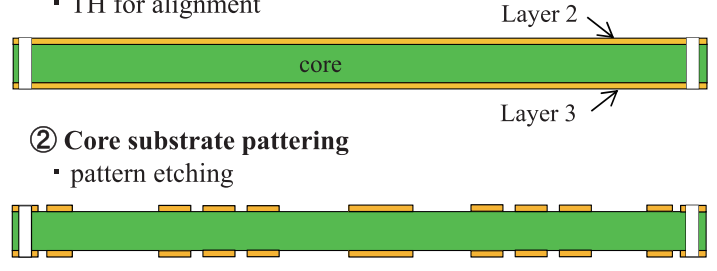

(3) Core substrate cutting

- $1 / 4$ size: $190 \mathrm{~mm} \times 250 \mathrm{~mm}$

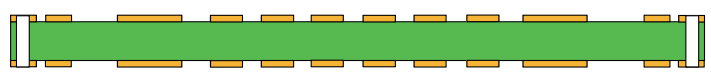

(4) Non conductive paste dispensing \& chip mounting - Piezo-resistor Si TEG: 3 x 3 chips

- paste curing: $150^{\circ} \mathrm{C}, 1 \mathrm{hr}$

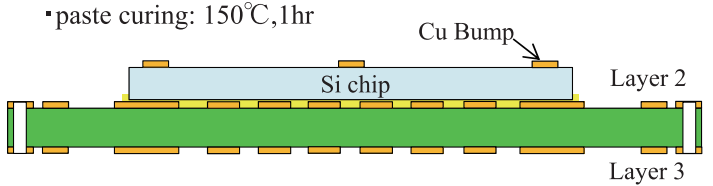

(5) Both side epoxy resin laminating

- ABF: build-up $(10 \mu \mathrm{m} t) /$ filling $(50 \mu \mathrm{m}+150 \mu \mathrm{m} t)$ resin

-vacuum laminating $+120^{\circ} \mathrm{C} \cdot 30 \mathrm{~min} / 180^{\circ} \mathrm{C} \cdot 1 \mathrm{hr}$ bake
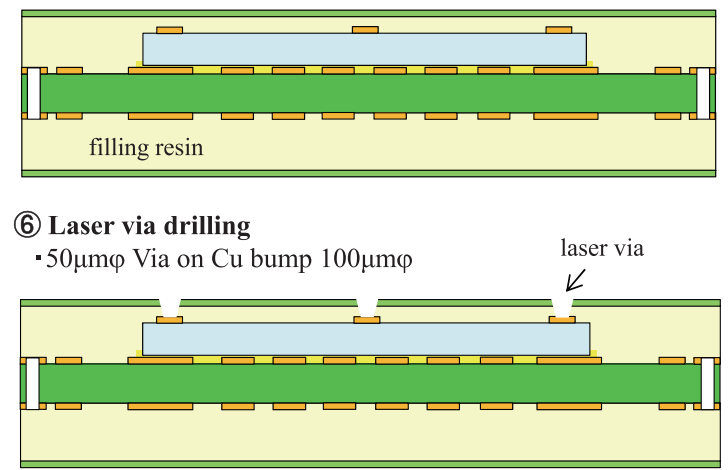

(7) Via filling $\&$ build-up layer pattering: semi-additive process -desmearing $\Rightarrow$ E'less $\mathrm{Cu} \Rightarrow$ DR pattern formation $\Rightarrow \mathrm{Cu}$ plating $\Rightarrow \mathrm{DR}$ removing $\Rightarrow$ seed layer etching



(8) Solder Resist patterning \& Singulation

$\cdot$ SR film laminating $\Rightarrow$ Photolithography $\Rightarrow$ Bake

$\cdot$ mechanically cutting into individual piece

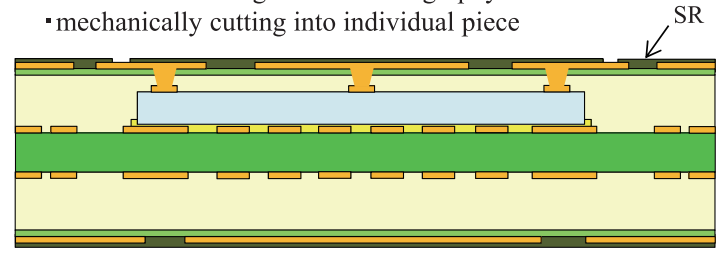

A. Core surface mounted type DES

(1) Core preparation \& mechanical drilling

- size : $407 \mathrm{~mm} \times 510 \mathrm{~mm} \times 0.2 \mathrm{~mm} t$

- TH drilling for alignment

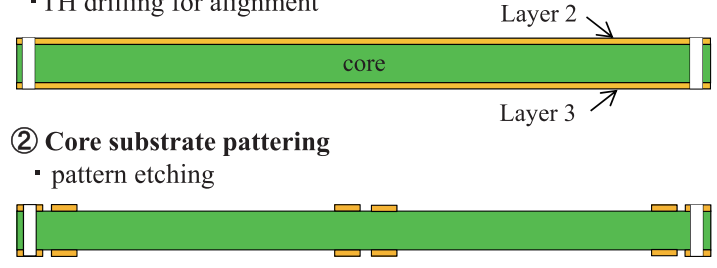

(3) Core substrate cutting \& cavity machining

- $1 / 4$ size: $190 \mathrm{~mm} \times 250 \mathrm{~mm}$

- cavity machining

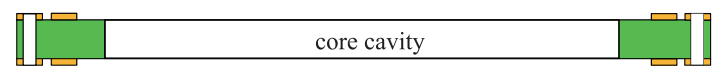

(4) Temporary adhesive tape laminating \& chip mounting - Piezo-resistor Si TEG: 3 x 3 chips

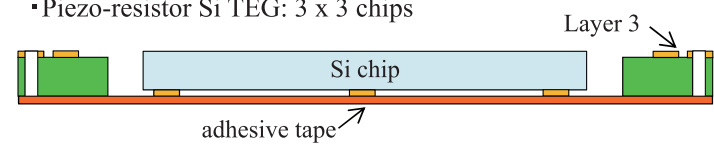

(5) Back-side epoxy resin laminating

- ABF:build-up $(10 \mu \mathrm{m} t) /$ filling $(50 \mu \mathrm{m} t)$ resin

- Vacuum laminating $\&$ air pressure pressing $\Rightarrow 120^{\circ} \mathrm{C}, 30 \mathrm{~min}$ bake

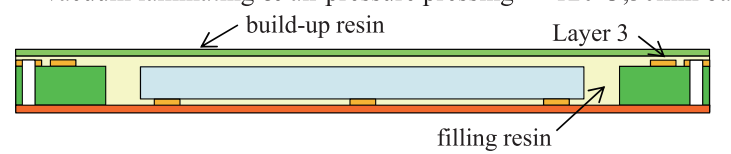

6) Adhesive tape peel off \& epoxy resin laminating

- build-up $(10 \mu \mathrm{m} t) /$ filling $(35 \mu \mathrm{m}$ or $50 \mu \mathrm{m} t)$

- Vacuum laminating \& air pressure pressing $\Rightarrow 180^{\circ} \mathrm{C}, 1 \mathrm{hr}$ bake

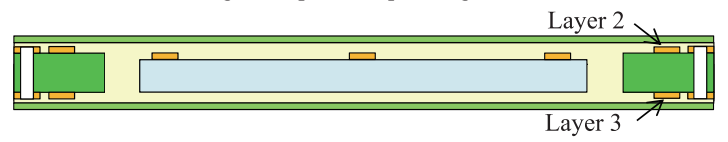

(7) Laser via drilling

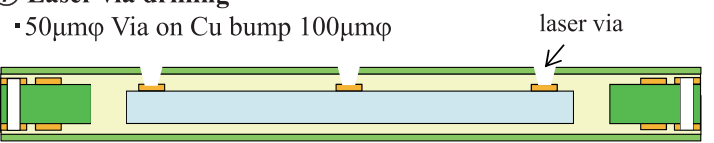

(8) Via filling \& build-up layer pattering: semi-additive process -desmearing $\Rightarrow$ E`less $\mathrm{Cu} \Rightarrow$ Photolithography $\Rightarrow \mathrm{Cu}$ plating

$\Rightarrow$ film resistor removal $\Rightarrow$ seed etching

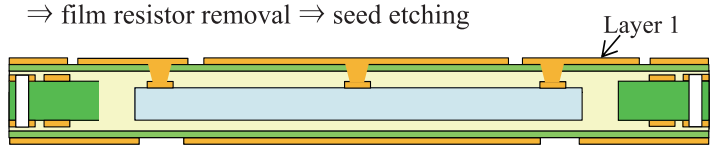

(9) Solder Resist patterning \& Singulation

-SR film laminating $\Rightarrow$ Photolithography $\Rightarrow$ Bake

- mechanically cutting into individual piece

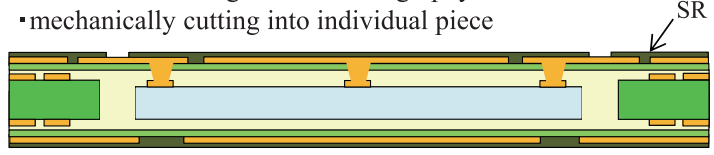

\section{B. Core cavity type DES}

Fig. 2 Schematic fabrication process flows of the core surface mounted type and the core cavity type DES.

color). The positions to be measured at the package level were identified from $\mathrm{A}$ to $\mathrm{H}$ and the other piezo-resistive sensors were omitted in Fig. 3. Each position of $A$ to $H$ has different distance from chip center and the residual stress variations as a function of the distance from chip center can be evaluated. The distances from chip center to several main positions are like as followings; A: $0.289 \mathrm{~mm}, \mathrm{~B}$ : $1.153 \mathrm{~mm}, \mathrm{E}: 1.847 \mathrm{~mm}, \mathrm{C}: 3.289 \mathrm{~mm}$, and D: $4.153 \mathrm{~mm}$. 
$\underline{9 \times 9 \mathrm{~mm} \text { size chip including } \mathrm{A} \sim \mathrm{H} \text { piezo-resistive sensor }}$

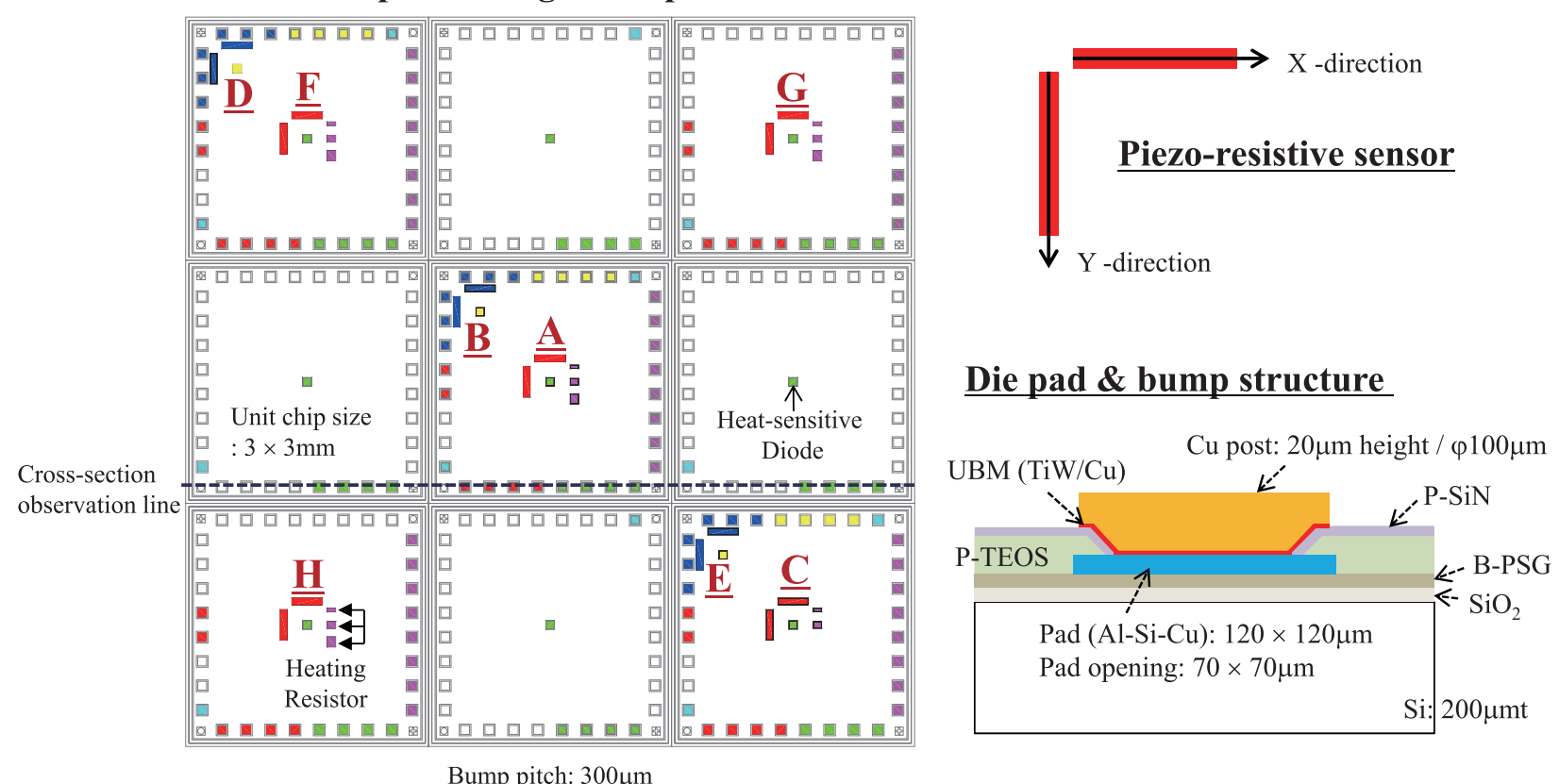

Fig. 3 Schematic image of piezo-resistive sensor embedded Si chips and schematic cross section of the die bump/pad area. ; all of $3 \times 3 \mathrm{~mm}^{2}$ unit chips have the same piezo-resistive sensors but the piezo- resistive sensors under the test are only indicated in the figure and related pads are colored.

The pad/bump structure of the chip was a $20 \mu$ m thick $\mathrm{Cu}$ bump with $\Phi 100 \mu \mathrm{m}$ formed on the $70 \mu \mathrm{m}$ pad opening. The chips were carefully ground down to $200 \mu$ m thickness taking care not to induce electrostatic damage on the piezo-resistive sensors. The chips were mounted using a flip-chip bonder (MD3500, Toray Engineering, Japan) with a placement accuracy of $\pm 5 \mu \mathrm{m}$. Before mounting, the resistance values of each piezo-resistive sensor of each chip were measured using the four point measurement method.

After mounting the chips, a two-layer structure of ABF (build-up resin: GX92K $(10 \mu \mathrm{mt})$ and filling resin: TH3L3 $(50 \mu \mathrm{mt}))$ was laminated. In the case of the core surface mounted type DES, both sides of the core were laminated simultaneously with a dielectric epoxy resin (Ajinomoto, ABF $60 \mu \mathrm{mt}$ ). However, in the case of the core cavity type DES, the epoxy resin was sequentially laminated from one side (back, layer 3) of the substrate core. The ABF laminating was accomplished in two steps: vacuum laminating (resin filling without voids) and atmosphere pressing (surface leveling). The laminated substrate was then pre-cured at $120^{\circ} \mathrm{C}$ for $0.5 \mathrm{~h}$ in an atmosphere oven. The temporary adhesion tape was then peeled off, and the sample treated with oxygen plasma for $180 \mathrm{~s}$ to remove any remaining adhesive. To form a symmetric built-up resin structure, the plasma-treated side (layer 2) was laminated with the same epoxy structure as layer 3 . After both sides of the core substrate were laminated, the epoxy resin was cured at $180^{\circ} \mathrm{C}$ for $1 \mathrm{~h}$. For the core cavity type DES, both sides of the laminated core substrate showed good surface planarity without any dimples around the cavity clearance.

Laser via drilling was accomplished using a Hitachi Via Mechanics UV- $\mathrm{CO}_{2}$ combined laser drilling machine. The UV laser (355 nm wavelength, $50 \mathrm{KHz} \mathrm{YVO}_{4}$ laser) was used to obtain vias with a diameter of $50 \mu$ m (maximum size of the via) on $100 \mu \mathrm{m} \mathrm{Cu}$ UBM (under bump metallurgy). To drill the designed via diameters, the pulse power was manipulated by $4.7 \mathrm{~W}$ with a mask size of 1.45 $\mathrm{mm}$. To prevent the target via size from increasing because of the heating effect, the laser drilling was performed using a cycling mode, that is, the 28 shots were implemented with 4 burst shots repeated for 7 cycles. Laser drilling often leaves undesirable byproducts known as smear. To remove smear from the bottom of the via and its surroundings, we used the conventional desmearing technique using a $\mathrm{KMnO}_{4}$ alkali chemical solution.

After desmearing, we performed via filling and $\mathrm{Cu}$ trace patterning. This was a semi-additive process with the following steps: the $\mathrm{Cu}$ seed layer was grown to a target thickness of $1 \mu \mathrm{m}$ for $45 \mathrm{~min}$ at $27^{\circ} \mathrm{C}$ using an ATS ADDCOPPER IW (OKUNO Chemical Industries, Japan) colloid including $\mathrm{Pd} / \mathrm{Sn}$ catalysts. Patterns were formed using negative type dry film (DF) photoresist (RD1225, Hitachi chemicals, Japan) lamination and photolithogra- 
phy. After that $\mathrm{Cu}$ electroplating for one hour with a DC current density of $1.5 \mathrm{~A} / \mathrm{dm}^{2}$ grew the $20-\mu$ m-thick plated $\mathrm{Cu}$ layer. The composition of the copper electroplating solution was $200 \mathrm{~g} / \mathrm{L} \mathrm{CuSO}_{4} 5 \mathrm{H}_{2} \mathrm{O}, 50 \mathrm{~g} / \mathrm{L} \mathrm{H}_{2} \mathrm{SO}_{4}$ and 50 $\mathrm{mg} / \mathrm{L} \mathrm{HCl}$. The commercial additives TOP LUCINA $\alpha$ (OKUNO Chemical Industries, Japan) were also added to the plating solution. The DF resist lift-off and seed layer etching process then followed. A solder mask was then laminated using a film of solder resist (SR; PFR-800, AUS410 Taiyo Ink), and Ni/Au was electrolytically plated on the electrode pads.

Each completed substrate was separated into a test unit, and the resistance value of each piezo-resistive sensor was measured again. Figure 4 shows a schematic image of the first $\mathrm{Cu}$ wiring layer after DES completion. The resistance of each piezo-resistive sensor at package level was measured using four-point measurement method. The initial resistance value of the piezo-resistive sensor used in this study is around $25 \mathrm{k} \Omega$ and the resistance variation by residual stress is up to several hundreds $\Omega$. The residual stress was calculated from the measured resistance value using the following equation:

$$
\sigma_{T_{o}}=\frac{1}{S} \frac{R_{1 T_{o}}-R_{o T_{o}}}{R_{o T_{o}}},
$$

where, $R_{o}$ is the initial resistance, i.e., resistance at the chip level, $R_{1}$ the resistance after embedded substrate completion, $S$ stress sensitivity, and $\sigma$ the stress in $\mathrm{MPa}$ unit. Because the resistance and sensitivity were very sensitive to the measurement environment, such as the temperature and light, the measurement was carried out in a

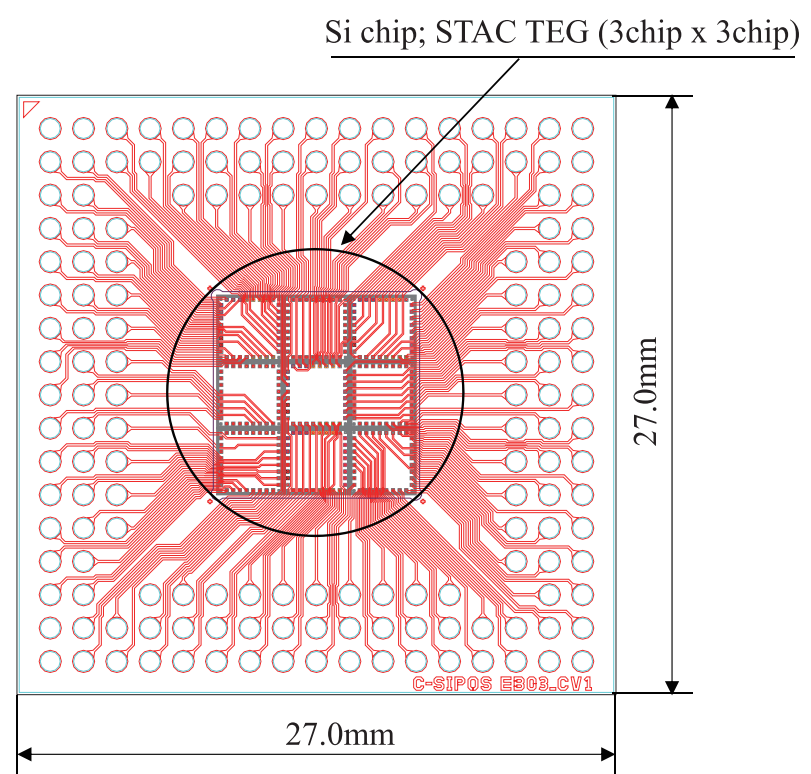

Fig. 4 Schematic image of the first $\mathrm{Cu}$ wiring layer of completed DES. dark room controlled at a constant temperature. The stress sensitivity at the temperature of $30^{\circ} \mathrm{C}\left(T_{0}\right)$ was assumed as $-0.001399((-)$ symbol is for p-type $\mathrm{Si})$ based on the chip supplier's calibration results. The stress value measured at different temperatures $\left(T_{1}\right)$ was obtained by the following equation:

$$
\sigma_{T_{1}}=\frac{1}{S}\left[\frac{R_{1 T_{o}}-R_{o T_{o}}}{R_{o T_{o}}}+\beta_{2}\left(T_{1}^{2}-T_{o}^{2}\right)+\beta_{1}\left(T_{1}-T_{o}\right)\right],
$$

where, $\beta_{1}$ and $\beta_{2}$ are temperature dependent correction factors of a piezo-resistance and $\beta_{1}$ is $1.57 \mathrm{E}-3 /{ }^{\circ} \mathrm{C}$ and $\beta_{2}$ is $-9.41 \mathrm{E}-8 /{ }^{\circ} \mathrm{C}^{2}$.

After the stress measurement, the structural analysis at the center and sides of the Si chip was conducted through cross section observation. Finally, the warpage of each sample was investigated using shadow moiré interferometry with the temperature changing between the room temperature and the $260^{\circ} \mathrm{C}$ solder reflow temperature.

\section{Results and Discussions}

\subsection{Residual stress evaluation}

Figure 5 shows the measurement results for the residual stress in each type of device embedded substrate. As shown in Fig. 5, the core surface mounted type DES shows the high tensile stress (about $100 \mathrm{MPa}$ ) in the center and the stress magnitude decreases to around $20 \mathrm{MPa}$ on moving outward from the chip center. Whereas, the core cavity type DES shows the small compressive stress between 10 $\mathrm{MPa}$ (at the chip center) and $30 \mathrm{MPa}$ (at the chip edge). The large difference between the $x$ - and $y$-directions was not observed for both types of DESs.

The process induced stress is well known as being

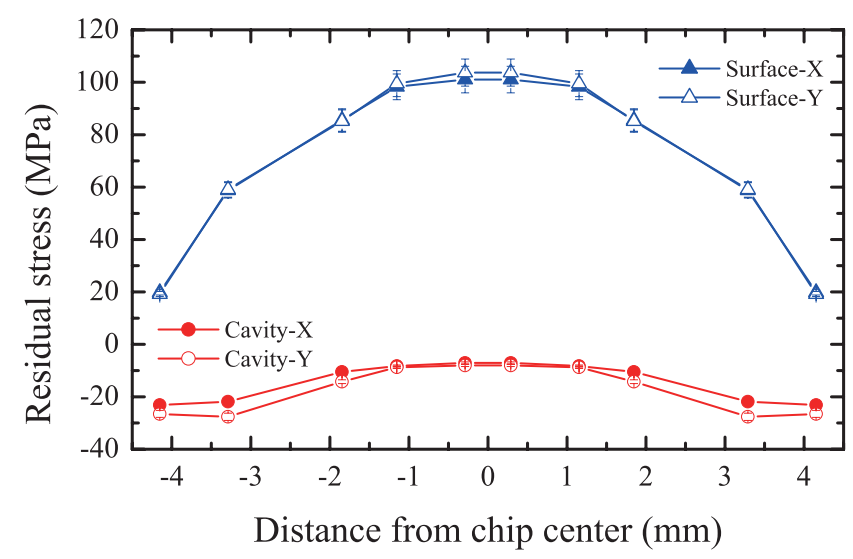

Fig. 5 Measured residual stress distribution of the core surface mounted type and core cavity type DES with FR4 core and $\mathrm{Cu}$ core. $\mathrm{A}$ to $\mathrm{H}$ measurement positions are translated to the distances from the chip center. 
occurred from the mismatch in the coefficient of thermal expansion (CTE) among the materials. The thermal loading, in this fabrication, was the result of the temperature difference between the plated $\mathrm{Cu}$ annealing temperature $\left(180^{\circ} \mathrm{C}\right)$ and the room temperature of $25^{\circ} \mathrm{C}$. The mismatches of CTE between the core and the $\mathrm{ABF}$ and/or the embedded Si chip and the $\mathrm{ABF}$ are considered the main reasons for the thermal stress. The representative material's relevant properties are summarized in Table 1 . For a core surface mounted type DES, the high tensile stress at the chip center area is explained easily by the lateral and vertical imbalance of the substrate structure. That is, the $\mathrm{ABF}$ thickness in the lateral direction is significantly differ- ent on the Si chip and on the core substrate surrounding it. Moreover, the structure in the vertical direction is different on the top and bottom of the Si chip. The ABF on the top of the chip was only $60 \mu \mathrm{m}$ thick, whereas the bottom of the chip consisted of various materials, such as a 7 $\mu \mathrm{m}$ thick paste layer, a $200 \mu \mathrm{mt}$ core with two $18 \mu \mathrm{mt} \mathrm{Cu}$ layers, and a $160 \mu \mathrm{mt}$ ABF layer. The thickness of each layer was established from the cross section as shown in Fig. 6(a). With the cooling from the $\mathrm{Cu}$ annealing temperature, shrinkage of the $\mathrm{ABF}$ on the bottom layer of the core was severe but on the upper layer of the core, because of the small quantity of $\mathrm{ABF}$ and Si chip stuck to the core, the shrinkage was restricted. This, consequently, induced

Table 1 Relevant mechanical properties of used various materials.

\begin{tabular}{c|c|c|c|c}
\hline Material & $\begin{array}{c}\text { Thermal expansion } \\
\text { Coefficient } \\
(\boldsymbol{\alpha} \text {-CTE) }\end{array}$ & $\begin{array}{c}\text { Young's modulus } \\
(\mathbf{G P a})\end{array}$ & $\begin{array}{c}\text { Thickness } \\
(\boldsymbol{\mu} \mathbf{m})\end{array}$ & $\begin{array}{c}\text { Glass transition } \\
\text { temperature } \\
\mathbf{T}_{\mathrm{g}}\left({ }^{\circ} \mathbf{C}\right)\end{array}$ \\
\hline $\mathrm{Si}^{*}$ & 3 & 107 & 200 & - \\
\hline $\mathrm{Cu}^{*}$ & 16.7 & 124 & 18 & - \\
\hline $\begin{array}{c}\text { FR4 core** } \\
\text { MCL-E-679FG } \\
\text { Hitachi Chemical }\end{array}$ & $\begin{array}{c}\mathrm{X}-\mathrm{Y}<120^{\circ} \mathrm{C} ; 13 \sim 15 \\
\mathrm{Z}<\mathrm{Tg} ; 22 \sim 33 \\
\mathrm{Z}>\mathrm{Tg} ; 140 \sim 170\end{array}$ & 25 & 200 & 175 (TMA) \\
\hline $\begin{array}{c}\text { ABF** } \\
\text { Ajinomoto fine Tech }\end{array}$ & $\begin{array}{c}21<\mathrm{Tg} \\
74>\mathrm{Tg}\end{array}$ & 7.9 & 50 & 156 (TMA) \\
\hline $\begin{array}{c}\text { SR** } \\
\text { PFR-800, AUS410 } \\
\text { Taiyo Ink }\end{array}$ & 60 & 3.2 & 25 & 105 (TMA) \\
\hline $\begin{array}{c}\text { Non-conductive } \\
\text { Paste** }\end{array}$ & 57 & 0.73 & 10 & \\
$\begin{array}{c}\text { EN-4900GC } \\
\text { Hitachi Chemical }\end{array}$ & & & & \\
\hline
\end{tabular}

* The Electronic Packaging Handbook edited by Glenn R. Blackwell; CRC Press

** From company catalogs and technical reports

Left side

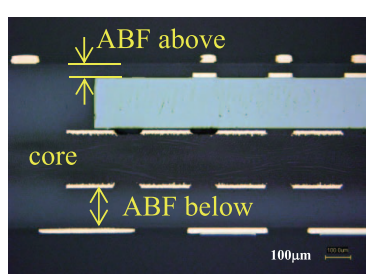

(b)

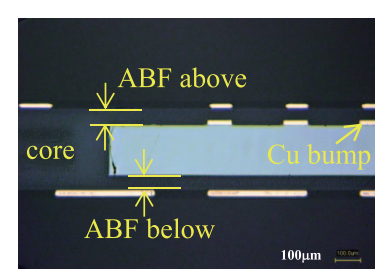

Center
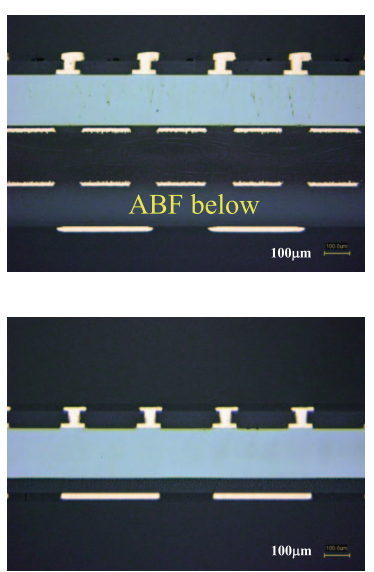

Right side
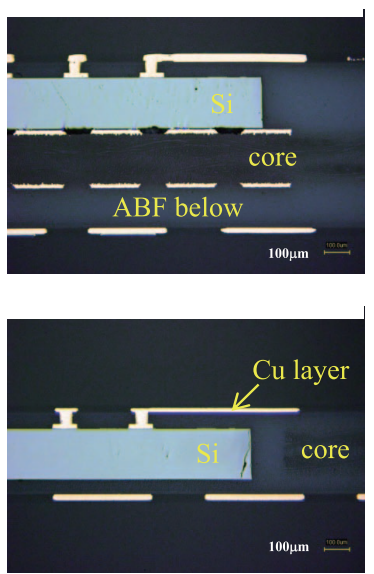

Fig. 6 Cross-section images of the core surface mounted type (a) and core cavity type (b) device embedded substrate. ; The cross-section observation line is designated on Fig. 3. 
high tensile stress on the chip surface.

Whereas, for core cavity type DES, the totally different result was obtained because the balanced structure was obtained above and below the chip and the embedded chip was well placed in a parallel position to the core without directly contacting it as shown in Fig. 6(b). The small compressive stress seemed to be induced from the thermal shrinkage difference in $\mathrm{ABF}$ resin above and below the embedded Si chip. Considering the difference in the ABF thickness, because the top of the chip was thicker than the bottom, the ABF thermal shrinkage on the top was greater and resulted in the compressive stress on its surface. As explained in the experimental details section, because the epoxy resin was laminated side by side sequentially for the core cavity type DES, the former laminated ABF (backside of the chip) was more able to flow into the cavity clearance more and was thinner than the latter layer. Therefore, the decrease in thickness of the former laminated side was affected by the cavity clearance size, and induced the change in the residual stress in the Si chip. The effect of cavity clearance on the residual stress is shown in Fig. 7. When increasing the dimension of the clearance the residual stress in the chip increased gradually, especially in its center area. The thickness of $\mathrm{ABF}$ above and below the chip was obtained from cross-section observation using laser microscope and the results including the thickness difference $(\Delta)$ between above and below ABF are summarized in Table 2. As expected, the ABF under the chip became thinner with the increasing cavity clearance dimension. This can be avoided using the thicker ABF film on the former laminated side, but in this study we did not optimize it. Another possible mechanism for the compressive residual stress on the chip might be related to the different thermal histories of the $\mathrm{ABF}$ on the top and bottom of the chip. However, because the backside ABF undergoes more only the pre-curing time of $0.5 \mathrm{~h}$ at $120^{\circ} \mathrm{C}$ below



Fig. 7 Measured residual stresses of various cavity type device embedded substrates with cavity clearances of $0.15 \mathrm{~mm} .0 .3 \mathrm{~mm}, 0.5$ $\mathrm{mm}$, and $1 \mathrm{~mm}$.

Table 2 ABF thickness above and below the embedded chip at the left-side ( $4 \mathrm{~mm}$ from the chip center), center, and right-side (4 mm from chip center) for various device embedded substrates.

\begin{tabular}{|c|c|c|c|c|c|c|c|c|c|c|}
\hline \multirow{3}{*}{$\begin{array}{c}\text { Type of } \\
\text { DES }\end{array}$} & \multirow{3}{*}{$\begin{array}{c}\text { Cavity } \\
\text { clearance } \\
(\mathrm{mm})\end{array}$} & \multicolumn{9}{|c|}{ ABF thickness (mm) } \\
\hline & & \multicolumn{3}{|c|}{ Left side } & \multicolumn{3}{|c|}{ Center } & \multicolumn{3}{|c|}{ Right side } \\
\hline & & above & below & $\Delta$ & above & below & $\Delta$ & above & below & $\Delta$ \\
\hline $\begin{array}{c}\text { Core Surface } \\
\text { Mounted } \\
\text { Type }\end{array}$ & - & 58.0 & 160.0 & \pm 102.0 & 55.0 & 160.0 & \pm 105.0 & 60.0 & 160.0 & \pm 100.0 \\
\hline \multirow{4}{*}{$\begin{array}{c}\text { Core Cavity } \\
\text { Type }\end{array}$} & 0.15 & 63.2 & 56.0 & \pm 7.2 & 66.0 & 58.4 & \pm 7.6 & 65.0 & 58.4 & \pm 6.6 \\
\hline & 0.3 & 72.0 & 46.0 & $\pm \mathbf{2 6 . 0}$ & 68.7 & 51.2 & $\pm \mathbf{1 7 . 5}$ & 70.0 & 46.4 & \pm 23.6 \\
\hline & 0.5 & 70.8 & 44.0 & $\pm \mathbf{2 6 . 8}$ & 68.0 & 50.8 & \pm 17.2 & 71.0 & 43.0 & $\pm \mathbf{2 8 . 0}$ \\
\hline & 1.0 & 72.8 & 38.5 & \pm 34.3 & 69.4 & 41.9 & \pm 27.5 & 75.6 & 38.5 & $\pm \mathbf{3 7 . 1}$ \\
\hline
\end{tabular}


the $T_{g}$ the influence of different cure shrinkage might be ignored in this study. Therefore, the thermal shrinkage difference because of the difference in $\mathrm{ABF}$ thickness seemed to be dominant and consequently the chip was under the compressive stress on its surface.

For the core cavity type DES, another interesting result was that the stress increased when moving outside the chip in opposite to the surface mounting type. This seemed to be caused by the things that the embedded chip was placed parallel to the core and the cavity clearance was inserted between the core and the embedded chip. That is, being different to the core surface mounted type having large structural imbalance in the vertical direction, the core cavity type DES has the small ABF thickness difference in the direction. Moreover, in the lateral direction, it has three different areas such as $\mathrm{ABF} /$ core/ABF structure area, cavity clearance area, and $\mathrm{ABF} / \mathrm{Si}$ chip/ABF structure area. Therefore, the stress can be higher at the chip edge area near to the $\mathrm{ABF} /$ core/ABF structure area which would deform more severely. However, this needs to be studied more to confirm.

So far, we have discussed how the residual stress in the DES can be minimized by realizing a balanced structure and placing the chip inside the core cavity in parallel. This controlled residual stress will decrease the warpage of the substrate, which we will discuss in detail in the next section.

\subsection{Warpage evaluation}

The substrate warpage is typically dependent on the properties of the dielectric materials such as Young's modulus, CTE, and $\mathrm{T}_{\mathrm{g}}$, the layer thickness of each component, and the $\mathrm{Cu}$ coverage ratio of each layer. For the device embedded substrate, the warpage can be further affected by the embedded device's mechanical properties and thickness. Figure 8 shows the warpage data obtained from the shadow moiré interferometry for the two types of device embedded substrates at room temperature before heat treatment. The measurement direction and surface are shown in Fig. 9 and the chip area and outer wiring area are also designated in the figure. The maximum warpages (the term of "coplanarity" in 3D images) of the core cavity type DES varied from $46 \mu \mathrm{m}$ up to $148 \mu \mathrm{m}$ depending on the clearance width, and were much smaller than the 238 $\mu \mathrm{m}$ of the core surface mounted type DES. As shown in Fig. 8, concave contours were observed in contrast to the convex contours of the core surface mounted type DES. To explain the warpage results, we believe that the residual stress induced during fabrication process was the main factor of the substrate warpage which can be easily confirmed from the residual stress data shown in Figs. 5 and 7. That is, we can relate the residual stress curves and properties to the warpage contours and magnitudes. For the core surface mounted type DES, the considerable tensile stress highly concentrated on the embedded chip center area, and the small stress at the chip edge, made the substrate severely warp convexly. Whereas, for the core cavity type DESs, a small compressive stress was observed from $10 \mathrm{MPa}$ at the center to $30 \mathrm{MPa}$ at the chip edge and resulted in the small concave warpage in the chip area. The warpage in the chip area of the core cavity type DES increased with increasing cavity clearance width, similar to the residual stress increasing, as shown in Fig. 7. In the outer wiring area, the different warpage contour compared to the center area, and asymmetric warpage between two diagonal directions, were observed for clearances of 0.15 and $0.3 \mathrm{~mm}$. However, the phenomena disappeared after heat treatment and cooling down back to $30^{\circ} \mathrm{C}$ as shown in Fig. 10. Figure 10 shows 3-D images of the warpages at the peak temperature of $260^{\circ} \mathrm{C}$ and at the returned temperature of $30^{\circ} \mathrm{C}$. Therefore, these were possibly induced by the small mechanical force added during the fabrication process.

The variation in warpage with temperature was also investigated. Figure 11 shows the temperature dependent warpage variation of various DESs. The temperature increased from $30^{\circ} \mathrm{C}$ to $260^{\circ} \mathrm{C}(\mathrm{Pb}$-free reflowing temperature) and then back to $30^{\circ} \mathrm{C}$. For the core surface mounted type DES, the warpage decreased with increasing temperature and at around $150^{\circ} \mathrm{C}$ changed from convex (Fig. $8(\mathrm{a})$ ) to concave warpage (Fig. 10(a)). Because the temperature of $150^{\circ} \mathrm{C}$ was equal to $\mathrm{T}_{\mathrm{g}}$ of $\mathrm{ABF}$ as shown in Table 1 , the transition seemed to be mainly dependent on $\mathrm{ABF}$. With increasing temperature, ABF expanded gradually and then abruptly above $T_{g}$. Because $A B F$ was much more on the back of the core, this induced compressive stress on the chip surface and made the substrate warp concavely. For the core cavity type DESs, the warpage showed quite complicated behavior with temperature as shown in Fig. 11. For some conditions, the warpage magnitude kept almost the same with increasing temperature and the transition from concave to convex was not observed. To explain this warpage behavior, first we consider the residual stress change from the $\mathrm{ABF}$ expansion with increasing temperature. In the case where the clearance was narrow enough, such as 0.15 and $0.3 \mathrm{~mm}$ clearance, the warpage behavior seemed to be decided mainly 

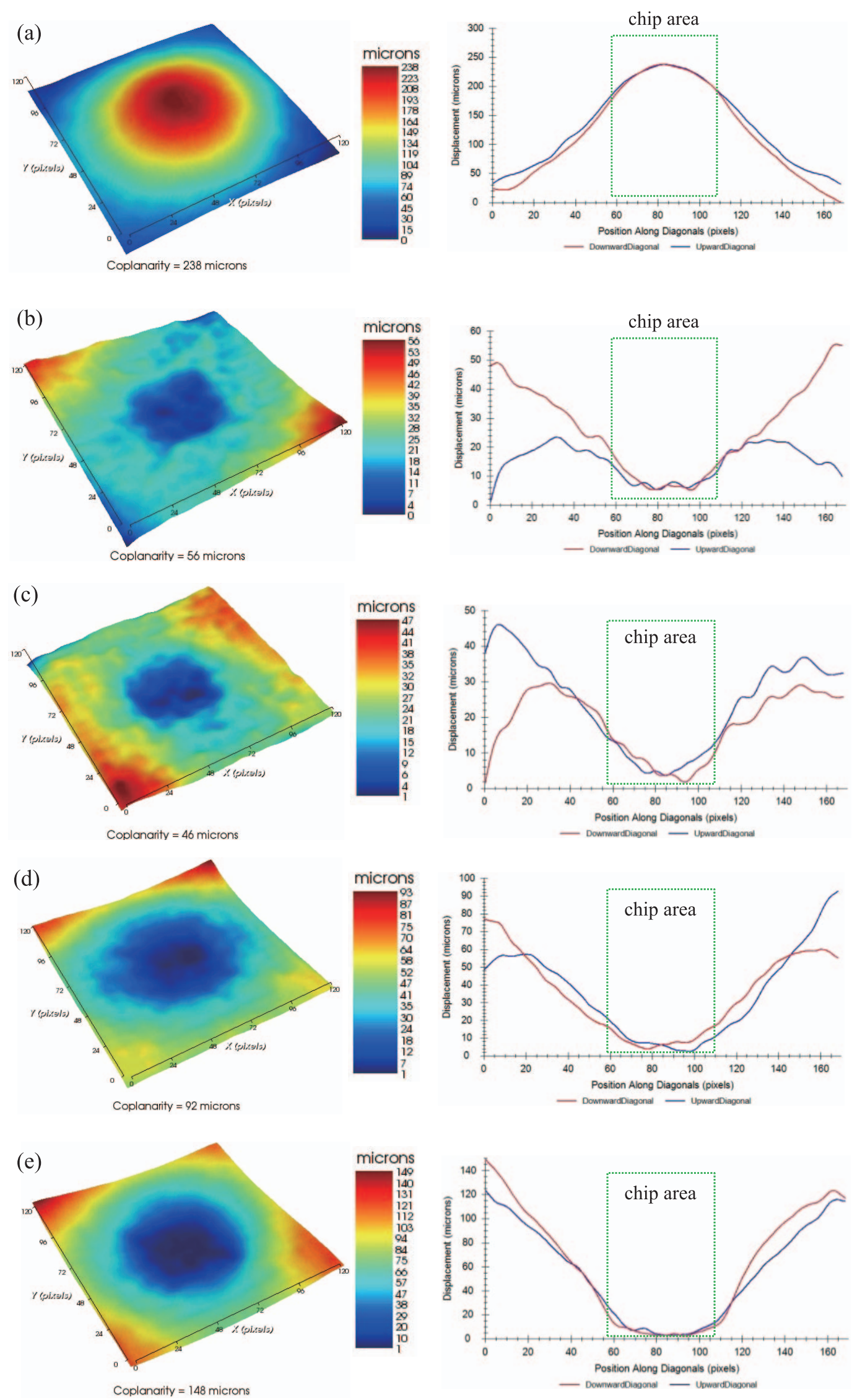

Fig. 8 Measured warpage of various device embedded substrates using shadow moiré interferometry before heat treatment. 3-D profiles and data along the two diagonal directions: (a) core surface mounted type DES, (b) core cavity type DES with $0.15 \mathrm{~mm}$ clearance, (c) core cavity type DES with $0.3 \mathrm{~mm}$ clearance, (d) core cavity type DES with $0.5 \mathrm{~mm}$ clearance, and (e) core cavity type DES with $1 \mathrm{~mm}$ clearance. 



Fig. 9 Warpage measurement line and the measurement surface notification of shadow moiré interferometry.

At $260^{\circ} \mathrm{C}$ temperature
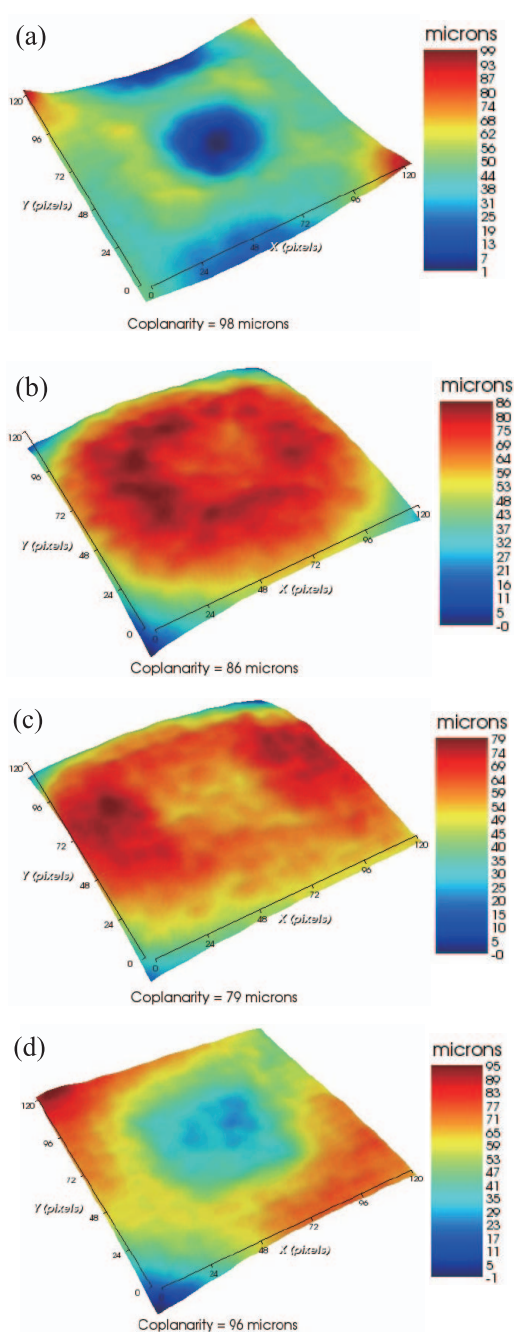

(e)
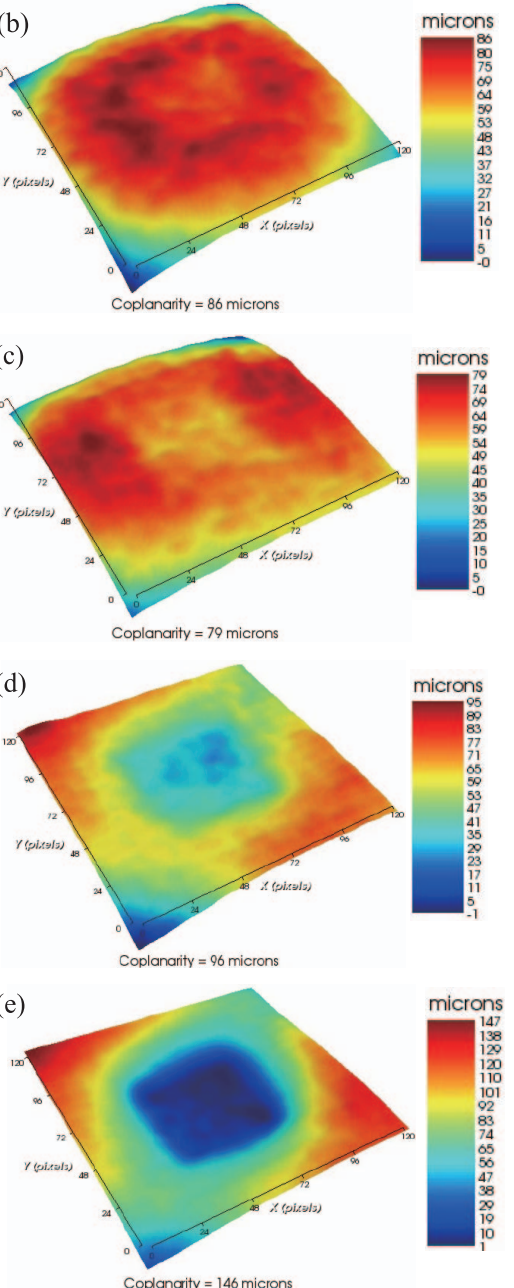

At $30^{\circ} \mathrm{C}$ temperature
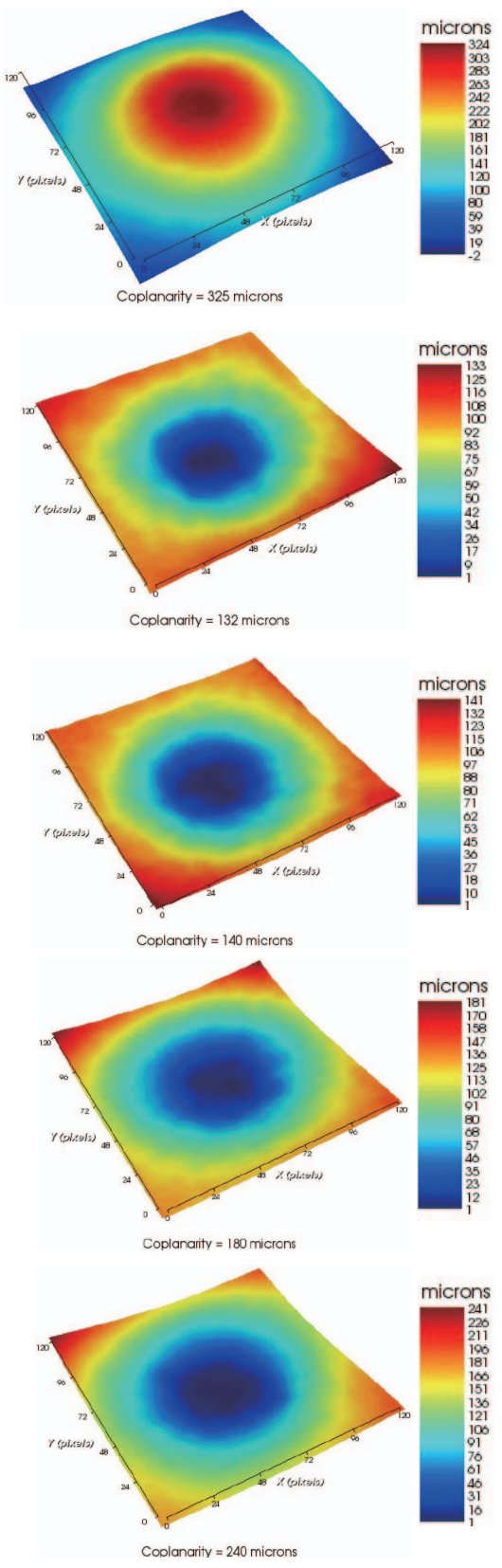

Fig. 10 3-D warpage profiles of various device embedded substrates using shadow moiré interferometry at the temperature of $260^{\circ} \mathrm{C}$ and returned temperature of $30^{\circ} \mathrm{C}$ : (a) core surface mounted type DES, (b) core cavity type DES with $0.15 \mathrm{~mm}$ clearance, (c) core cavity type DES with $0.3 \mathrm{~mm}$ clearance, (d) core cavity type DES with $0.5 \mathrm{~mm}$ clearance, and (e) core cavity type DES with $1 \mathrm{~mm}$ clearance. 


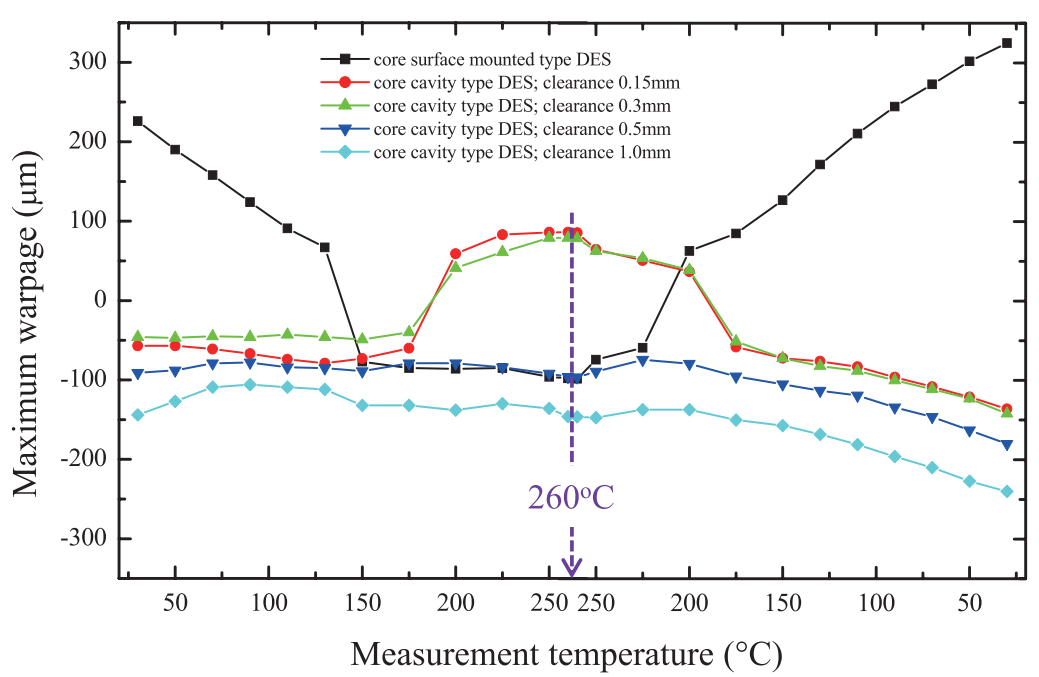

Fig. 11 Maximum warpage variation of various device embedded substrates with increasing measurement temperature from $30^{\circ} \mathrm{C}$ to $260^{\circ} \mathrm{C}$ and back to $30^{\circ} \mathrm{C}$. Positive direction is convex warpage and negative direction is concave warpage.

by the difference in the ABF expansion between the top and bottom of the embedded chip and/or core (ABF was thicker on the top side of the chip and core). However, with increasing clearance width, the increased distance to the core wall and the increased ABF volume in the cavity area seemed to affect the warpage temperature performance. For the possible mechanism of the unchanged concave contour up to the reflow temperature, we are considering a separate behavior between the chip area and the outer wiring area.[21] That is to say, although quite large amounts of stress or stress release seemed to be necessary to induce the warpage transition in the chip area, by increasing the cavity clearance width, the large stress induced in the outer wiring area had no influence up to the chip area. This was possibly because the ABF had quite a low Young's modulus and ABF in the cavity clearance could absorb the deformation force. However, because the role of the $\mathrm{ABF}$ in the cavity clearance is still questionable and the warpage behavior in the wiring area cannot be discussed in enough detail in this study, the detailed discussion will remain for future study. Nevertheless, this result is interesting and valuable, in that if we optimize the $\mathrm{ABF}$ thickness above and below the embedded chip and the cavity clearance width, we can obtain very low warpage without variation up to the reflow temperature.

Until now, we have discussed how the warpage of a device embedded substrate is closely related to the residual stress during the fabrication process. However, because measurement the residual stress was limited to the embedded chip region, some phenomena such as the asymmetric warpage and the different temperature performance according to the cavity clearance width could not be clearly explained only by the residual stress in the embedded chip. Nevertheless, it was apparent that the residual stress can be controlled easily by obtaining a symmetric and balanced structure using a core cavity type design and the controlled residual stress can decrease the substrate warpage significantly. Additionally, to alleviate residual stress and warpage in an organic substrate the balanced structure in the substrate is more important than improving each material's mechanical properties.

\section{Conclusion}

We demonstrated, using a piezo-resistive sensor embedded Si chip, that the core cavity type device embedded substrate has very small residual stress and good warpage performance. The residual stress in the embedded chip was mostly dependent on the balance of the ABF thickness above and below the embedded chip. The warpage properties of the as-received device embedded substrates could be explained by relating them to the residual stress evaluation. However, for the core cavity type DES, the temperature performance of the substrate warpage showed different behavior with increasing cavity clearance width. Because the measurement of the residual stress in the embedded chip region cannot explain the warpage performance in the full area of the package for a cavity clearance width of more than $0.5 \mathrm{~mm}$, the effect and role of the cavity clearance on warpage should be investigated in more detail. Notwithstanding, it is apparent that the core cavity 
type DES has the superiority to the core surface mounted type DES in regard to the residual stress and the warpage performance.

\section{Acknowledgment}

The authors would like to thank Ajinomoto Fine Technology (AFT) for their supply of ABF films and kind advice on optimizing the ABF lamination condition, and for their cooperation on substrate warpage evaluation.

\section{References}

[1] A. Ostmann, D. Manessis, J. Stahr, M. Beesley, M. Cauwe, and J. D. Baets, "Industrial and Technica1Aspects of Chip Embedding Technology," $2^{\text {nd }}$ Electronics System-integration Technology Conference (ESTC), Greenwich, UK, Sept. 2008, pp. 315-320.

[2] G. J. Vandentop, S. N. Towle, H. Braunisch, C. Hu, and R. D. Emery, "Bumpless Build-Up Packaging," ASME International Mechanical Engineering Congress and Exposition, Nov. 2001.

[3] H. Braunisch, S. N. Towle, R. D. Emery, C. Hu, and G. J. Vandentop, "Electrical Performance of Bumpless Build-Up Layer Packaging," $52^{\text {nd }}$ Electronic Components and Technology Conference (ECTC), May. 2002, pp. 353-358.

[4] T. Waris, R. Touminen, J. Kivilahti, "Panel-sized integrated module board manufacturing," Proc. Polytronics Conference, Potszam, Germany, Oct. 2001, pp. 218-223.

[5] A. Ostamann, A. Neumann, P. Sommer, H. Reichl, "Buried components in printed circuit boards," Advancing Microelectronics, May/Jun. 2005, pp. 13-18.

[6] D. Manessis, L. Boettcher, A. Ostmann, R. Aschenbrenner, and H. Reichl, “Chip embedding technology developments leading to the emergence of miniatureized system-in-packages," Proceedings in the $60^{\text {th }}$ Electronics Components \& Technology Conference (ECTC), LasVegas, NV. USA, Jun. 2010, pp. 803-810.

[7] C.-T. Ko, S. Chen, C.-W. Chiang, T.-Y. Kuo, Y.-C. Shih, and Y.-H. Chen, "Embedded Active Device Packaging Technology for Next-Generation Chip-in-Substrate Package, CiSP," Proceedings in the $56^{\text {th }}$ Electronic Components and Technology Conference (ECTC), San Diego, CA. USA, May/Jun. 2006, pp. 322-329.

[8] F. Liu, V. Sundaram, S. Min, V. Sridharan, H. Chan, N. Kumbhat, B.-W. Lee, and R. Tummala, "Chip-last
Embedded Actives and Passives in Thin Organic Package for 1-110 GHz Multi-Band Applications," Proceedings in the $60^{\text {th }}$ Electronic Components \& Technology Conference (ECTC), LasVegas, NV. USA, Jun. 2010, pp. 758-763.

[9] K. Tanaka, N. Kurashima, H. Iizuka, K. Ooi, Y. Machids, T. Koyama, "Warpage and Electrical Performance of Embedded Device Package, MCeP,” $61^{\text {st }}$ Electronic Components \& Technology Conference (ECTC), Lake Buena Vista, FL. USA, 31 May/Jun. 2011, pp. 1377-1383.

[10] Y. Han, O. Horiuchi, S. Hayashi, K. Nogita, Y. Katoh, and H. Tomokage, "Process Feasibility and Reliability Performance of Fine Pitch Si Bare Chip Embedded in Through Cavity of Substrate Core," IEEE Trans. Compon. Packag. Technol., Vol. 5, No. 4, pp. 551-561, 2015.

[11] Y. Ahn, J. Kim, C. Song, G. Han, J. Yoon, and C. Lee, “Copper Foil Exposed Structure for Thin PoP Warpage Improvement," Proceedings in the $65^{\text {th }}$ Electronic Components \& Technology Conference (ECTC), San Diego, CA. USA, May. 2015, pp. 877881.

[12] J. Zheng, E. Zhou, L. Wang, M. Aldrete, R. Kumar, and A. Syed, "Relative and Absolute Warpage Modeling on Molded Packages," Proceedings in the $65^{\text {th }}$ Electronic Components \& Technology Conference (ECTC), San Diego, CA. USA, May. 2015, pp. 15381545.

[13] C.-C. Chen, M.-Z. Lin, G.-C. Liao, Y.-C. Ding, and W.-C. Cheng, "Balanced Embedded Trace Substrate Design for Warpage Control," Proceedings in the $65^{\text {th }}$ Electronic Components \& Technology Conference (ECTC), San Diego, CA. USA, May. 2015, pp. 193-199.

[14] J. C. Suhling and R. C. Jaeger, "Silicon Piezoresistive Stress Sensor and Their Application in Electronic Packaging,” IEEE sensors Journal, Vol. 1, No. 1, pp. 14-30, 2001.

[15] M. Koganemaru, T. Ikeda, and N. Miyazaki, "Evaluation of Residual Stress in Semiconductor Chips during Resin-molding Process using Peizoresistive Test Chips and a Finite Element Analysis Method,” Japan Institute of Electronics Packaging, Vol. 9, No. 3, pp. 186-194, 2006.

[16] D. Lee, S. Kim, M. Kim, O. Bae, K. Kim, and H. Kang, "Fabrication of Die Embedded Substrate and Mechanical Stress Evaluation at Active Area of the 
Embedded Die," $10^{\text {th }}$ Electronics Packaging Technology Conference (EPTC), Dec. 2008, pp. 224-229.

[17] C. S. Smith, "Piezoresistance Effect in Germanium and Silicon,” physical Review, Vol. 92, No. 1, pp. 42-49, 1954.

[18] A. Hamada, T. Furusawa, N. Saito, and E. Takada, “ A new aspect of mechanical stress effects in scaled MOS devices,” IEEE Trans. Electron Devices, Vol. 38, No. 4, pp. 895-900, 1991.

[19] K. Matsuda and Y. Kanda, "Stress-induced effects on depletion-layer capacitance of metal-oxide-semiconductor field-effect transistors,” Appl. Phys. Lett., Vol.
83, No. 21, pp. 4351-4353, 2003.

[20] Y. Han, M. Koganemaru, T. Ikeda, N. Miyazaki, W. Choi, and H. Tomokage, “ Influence of uniaxial mechanical stress on the high frequency performance of metal-oxide-semiconductor field effect transistors on (100) Si wafer,” Appl. Phys. Lett., Vol. 96, pp. 213515-3, 2010.

[21] Y. Nakashima, K. Kikuchi, K. Mori, D. Ohshima, and S. Yamaichi, "Warpage Mechanism of Thin Embedded LSI Packages," Transaction of The Japan Institute of Electronics Packaging, Vol. 3, No. 1, pp. 47-56, 2010. 




Younggun Han was born in Sunchon, Korea, in 1975. He received Ph.D. degree in metallurgical engineering from Korea University, Seoul, Korea, in 2004. He has joined in Hajime Tomokage Research Group in Fukuoka University, Fukuoka, Japan since 2008, working on advanced packaging, $\mathrm{Si}$ piezo-resistive property evaluation, device embedded substrate development, and millimeter wave transmission property evaluation and simulation.

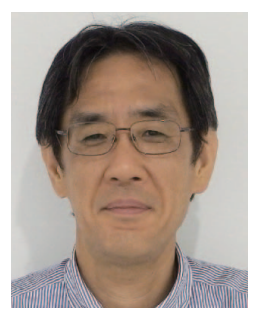

Osamu Horiuchi received B.S. degree in applied chemistry from Yamanashi University, Kofu, Japan, in 1986. He has been a Researcher in Hajime Tomokage Research Group in Fukuoka University, Fukuoka, Japan since 2008, working on advanced packaging, especially design of Si test element group (TEG) chip, device embedded substrate development and ultra-fine patterning on organic substrate. Prior to joining Tomokage's group, he was a Research Engineer at Hitachi ULSI Systems in Tokyo, Japan, and his main interest is the field of semiconductor packaging technology.

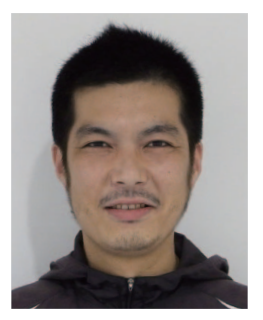

Shigehiro Hayashi was received Ph.D. degree in electronics engineering from Fukuoka University, Fukuoka, Japan, in 2013. He joined a plating company in Fukuoka, Japan, in 2003, where he was engaged in the development and manufacturing of surface finishing materials for SMDs such as 0603 and 0402 devices and the electrodes on semiconductor devices. Since 2011, he has been a Researcher in the Fukuoka Industry, Science and Technology Foundation, Japan. His research interests include advanced packaging, such as device embedded substrate. Especially, his main interests are electroless and electro-plating process.

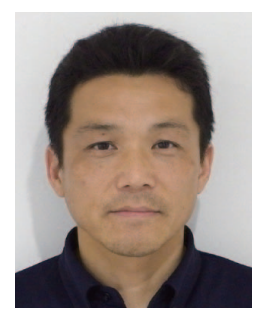

Kanta Nogita was born in Fukuoka, Japan in 1965. He received Engineering Degree in metal engineering from Chiba Institute of Technology. As for his four employment records, in the first company, he joined as lead-frame packages and ball grid array (BGA) packages development engineer in Mitsui Hightech from1989 to 2001. The second, he joined as system-in-a-packages (SiP) development engineer in SONY Semiconductor Kyushu, Oita, Japan from 2001 to 2005. The third, he was a technical adviser in Kitakyushu Foundation for the Advancement of Industry, Science and Technology (FAIS), and managed one of the Japan national research and development projects from 2006 to 2011. Finally, he has joined Fukuoka Industry Science and Technology Foundation since 2011. Up to now, he is engaging in the development management for high-density JISSO technologies in Research Center for Three-Dimensional Semiconductors.

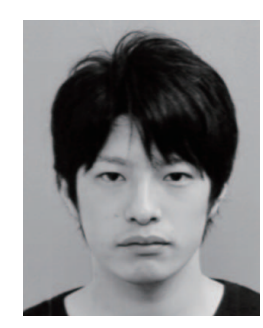

Kyosuke Nanami was born in Tokyo, Japan in 1991. He received B.S. degree in electronics engineering and computer science from Fukuoka University and now is pursuing M.S degree in the same field.

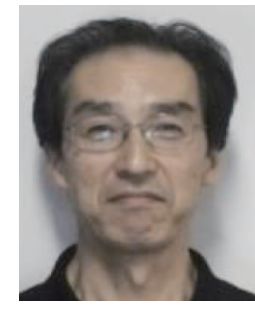

Yoshihisa Katoh received Doctor degree in engineering from Shizuoka University, Japan, in 2011. He has been a Professor with Hajime Tomokage Research Group in Fukuoka University, Fukuoka, Japan since 2012, working on advanced packaging, such as embedded device substrate development, package characterization, reliability test, and simulation. Prior to joining Tomokage's group, he was a Research Engineer with a MEIKO ELECTRONICS Co., Ltd., CMK CORPORATION, Gunma, Japan and NIPPON STEEL \& CHEMICAL Co., Ltd., Kanagawa, Japan. Where, he worked on the research and development of new printed wiring board (PWB) and new functional resin materials.

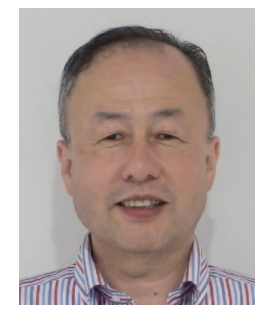

HajimeTomokage was born in Yamaguchi, Japan in 1953. He received B.E., M.E., and Doctor of Engineering degrees in electrical engineering from Kyushu University, Fukuoka, Japan in 1977, 1979, and 1982, respectively. He joined Fukuoka University as a Lecturer in 1982. Since 1992, he has been a Professor in Department of Electronics Engineering and Computer Science, Fukuoka University. His research area covers nanotechnology with carbon materials and high-frequency System-in-a-Package (SiP) design and evaluation. Dr. Tomokage had been the President of the Japan Institute of Electronics Packaging from 2009 to 2011. He has been the Chairman of the International Workshop on Microelectronics Assembling and Packaging, since 2001 . 